\title{
El problema de la extensión del ámbito eidético: Parménides y República VII
}

MARIo SHeING

Pontificia Universidad Católica del Perú

https://doi.org/10.18800/estudiosdefilosofia.201701.006

Resumen: Algunos intérpretes de Platón consideran que algunos pasajes de la República y el Parménides nos proveen de un criterio para delimitar la extensión del ámbito ediético, es decir, para saber qué tipos de Ideas hay y qué tipos no. Hay ideas solo para pares de propiedades opuestas, como "grande" y "pequeño", ya que la pequeñez no es lo que aparece a los sentidos, pues en cada instancia sensible suya la encontramos mezclada con su opuesto, la grandeza. Contrariamente, aquellas cosas que son tal como aparecen a los sentidos, como los dedos, no tienen un eidos. Sin embargo, una lectura más cuidadosa de los pasajes relevantes, tomando en cuenta lo que Sócrates dice sobre la multiplicidad y unidad de las ideas en República 476a, nos mostrará lo equivocado de esta interpretación.

Palabras clave: Republica, Parménides, ideas, opuestos, percepción sensible.

Abstract: "The Problem of the Extension of the Eidetic World: Republic VII and Parmenides". For some of Plato's commentators some passages of the Republic and the Parmenides provide a clear guideline regarding the extension of the noetic "world", namely, a criterion that allows us to know what kind of Platonic forms there are, and which there are not. There are forms only for a pair of opposite properties such as "big" and "small"; indeed, smallness itself is not what appears to the senses, since each sensible instance of smallness appears "mixed" with its opposite, bigness. On the contrary, things that are perceived by the senses such as fingers, do not have an eidos. However, a more careful reading of the relevant passages, taking into account what Socrates says in 476 a about the unity and multiplicity of the forms, will show us the incorrectness of this interpretation.

Key words: Republic, Parmenides, Platonic forms, opposites, sensory perception. 


\section{§ 1. Introducción}

Es opinión de algunos intérpretes que, en el periodo medio de su producción, Platón (i) solo admitía la existencia de Ideas para pares de propiedades opuestas, y no para algún otro tipo de ellas y, consecuentemente, (ii) admitía la existencia de al menos una clase de objetos a los que no correspondía una Idea'. Para estos intérpretes, esta hipótesis se vería sugerida y confirmada, por una parte, en el pasaje de República VII 523a-524, en el pasaje del examen de tres dedos, y en Parménides I30a-I3 la, en aquél pasaje conocido por abordar el tema de la extensión del ámbito eidético.

El criterio que ambos pasajes establecerían para decidir sobre qué cosas existe una Idea sería el siguiente: algunas cosas son tales como los percibimos, mientas que otras no, pues lo mismo puede aparecer como tal y como su opuesto. Tres dedos, en tanto dedos, son tales y como los vemos, pero en cuanto a su grandeza o pequeñez, el mismo dedo aparece como pequeño y grande a la vez, en relación con los otros. De modo que la grandeza y la pequeñez deben ser algo distinto de aquellas cosas que aparecen como grandes y pequeñas a la vez. Pero no así con respecto a los dedos, pues ninguno de ellos aparece como no siéndolo. Una lectura cuidadosa y contextualizada de los pasajes, sin embargo, mostrará que estos no establecen un criterio concluyente. Las primeras dos secciones analizan el pasaje de Parménides y de República VII, respectivamente. La tercera sección expone el conocido "argumento de los opuestos", propuesto para demostrar la existencia de solo un tipo determinado de Ideas, las correspondientes a predicados opuestos como 'grande' y 'pequeño'. En la misma sección se ofrecen reparos con respecto al argumento y a la posibilidad de interpretar el pasaje como ofreciendo uno. La cuarta sección ofrece una interpretación distinta del pasaje de los tres dedos en base a la crítica de la sección anterior. La sección quinta expone la posibilidad de un dominio de objetos a los que no les correspondería una Idea, una consecuencia de la interpretación que se busca criticar. Finalmente, la sección sexta ofrece razones para descartar, concluyentemente, la interpretación que se ha

I Por uniformidad de estilo, utilizaré el término "Idea” (con mayúscula) para referirme a una forma platónica. La ocurrencia del término "idea” (con minúscula) referirá a un contenido mental. 
venido criticando a partir de la consideración de otros detalles de los pasajes no tomados en cuenta.

\section{$\S 2$. Pelo, barro, agua y fuego son como los vemos}

El problema de la extensión del mundo eidético es abordado en el pasaje I30a-I3la del Parménides. Allí, Parménides pregunta al joven Sócrates si, además de Ideas de lo justo, de lo bello, de lo bueno y de otras de ese tipo, admite también Ideas como la Idea de Hombre, "separada de nosotros y todos cuantos son como nosotros" (Platón 2015c, I30c), Idea de Fuego o de Agua. Sócrates confiesa que muchas veces se ha encontrado en dificultades al respecto. Parménides insiste: ¿qué hay con respecto a cosas como pelo, barro y basura? Son cosas que parecen ridículas, despreciables y sin ninguna importancia; sin embargo, idebe admitirse una Idea para ellas, diferente y separada?, io no?

Sócrates, incómodo, responde: “iDe ningún modo!”. De ningún modo porque, aunque estas cosas son, son solo lo que vemos (2015c, 130d); pensar que hay una Idea de ellas es una cosa absurda y, aunque ya se ha sentido atormentado por "la cuestión de decidir si lo que se da en un caso no debe darse también en todos los casos" (20I5c, I30d), Sócrates confiesa que, por temor a perderse y caer en una necedad sin fondo, abandonó tales investigaciones.

Más allá de cierta indisposición personal, Sócrates parece tener una razón para rechazar Ideas como la de pelo, barro y basura: estas cosas, dice, son tales como las vemos. Un pelo no se muestra a la vista como otra cosa que un pelo, el barro y la basura no se muestran como otras cosas. Lo mismo parece ser el caso con un hombre, con el agua y el fuego: cuando son vistos, un hombre no aparece como otra cosa que un hombre, y así con el agua y el fuego.

Una piedra o un palo tampoco aparecen distintos a como los vemos. Sin embargo, dos palos iguales, si bien no se muestran como otra cosa que palos, sí pueden aparecer iguales para uno y desiguales para otro. O iguales para mí en este momento y desiguales en otro momento. $O$, más interesante, uno de ellos puede parecer igual a un tercero, pero este no al otro, de modo que los tres palos aparecen como iguales y desiguales a la vez. Lo mismo puede 
suceder con un par de piedras iguales. Pero, más allá de las piedras y los palos iguales, ¿qué hay con respecto a lo igual (y lo desigual) en sí mismo?

Palos y piedras que son iguales se diferencian al menos en un aspecto fundamental de lo igual en sí mismo: (i) piedras y palos que son los mismos algunas veces aparecen a uno iguales y a otro no, mientras que (ii) es imposible que las cosas iguales en sí mismas se muestren como desiguales, o que la igualdad aparezca como desigualdad (Platón 2015a, 74a-c). Ahora bien, si la igualdad fuera idéntica con las cosas perceptibles (sensibles, visibles) que son iguales (e.g. palos y piedras), entonces percibir la igualdad sería percibir cosas iguales. Ahora, dado que cosas iguales algunas veces aparecen iguales y otras, desiguales, entonces la igualdad algunas veces aparecerá igual y otras veces desigual. Pero ello es absurdo (White 1992, 280-28I). En consecuencia, las cosas iguales y lo igual en sí no son lo mismo. Lo igual, al parecer, no es lo que vemos igual.

Descubrimos así que la igualdad en sí es algo distinto de las cosas iguales. La igualdad no es tal como la vemos. De esta manera, tenemos, al parecer, dos clases de objetos: por una parte, objetos como (A) hombres, agua, fuego, maderos, piedras, pelos; por otra parte, objetos como (B) cosas/acciones bellas, cosas/acciones justas, cosas iguales. La razón por la que el joven Sócrates acepta que a los objetos de la clase B les corresponde Ideas (o, en todo caso, que a las cosas bellas, a las acciones justas, a las cosas iguales, les corresponde una Idea) es que lo que la belleza, la justicia y la igualdad son no son las cosas bellas, justas e iguales que vemos (o percibimos por los sentidos) en nuestra experiencia ordinaria. La clase de objetos A, por el contrario, sí parecen ser lo que vemos, pues no aparecen como siendo otra cosa ${ }^{2}$. Teniendo ello en cuenta debemos preguntarnos si es que es este un criterio para decidir el rango del

2 Incluso Sócrates parece dividir esta clase entre objetos más o menos indignos que otros, y parece ser que es la vileza de objetos tales como pelos y barro lo que le afecta y le haga rechazar la posibilidad de que posean un عídos. Para los propósitos de este ensayo no es importante seguir esta pista. Sin embargo, para Scoon (1942, II7), esta es la clave para responder por qué Sócrates duda, por un lado, y rechaza, por otro, la posibilidad de cierto tipo de ideas de ciertas clases de objetos. La falta de nobleza de algunas entidades es justamente lo que hace difícil que Sócrates admita una Idea para ellas, ya que compromete un aspecto de la teoría de las Ideas que encontramos en los diálogos medios y tempranos: el hecho de que las Ideas sean paradigmas a los cuales las instancias sensibles aspiran. Naturalmente, pensar en el paradigma de barro o en el pelo ideal al cual todos los pelos aspiran puede ser la clase de sinsentidos en los cuales Sócrates teme caer. 
dominio de las Ideas: iacaso solo hay Ideas para cosas que no son como las vemos?, ¿no hay ideas para cosas que sí son como las percibimos?

\section{$\S 3$. Comunicaciones extrañas}

Algunos intérpretes han llamado la atención sobre el pasaje 523a-524 de República VII al momento de decidir la cuestión que nos ocupa. Se ha dicho que allí Platón ofrece una prueba de la existencia de las Ideas y, correspondientemente, del tipo de Ideas que existen. En mi opinión, sin embargo, el pasaje es el relato de una experiencia cognitiva específica. Sócrates distingue allí entre objetos de la sensación tales que "no invitan a la inteligencia a examinarlos, por ser ya suficientemente juzgados por los sentidos" (Platón 2006, 523b); y otros objetos que "la invitan insistentemente a examinarlos, porque los sentidos no dan nada aceptable" (2006, 523b). Los primeros son aquellos que "no desembocan al mismo tiempo en sensaciones contradictorias" (2006, 523b). Los que sí, son aquellos que efectivamente llaman a la inteligencia, pues "si son impresionados tanto de cerca como de lejos, los sentidos no indican que el objeto sea más bien esto que lo contrario” (2006, 523c).

Así, por ejemplo, si uno ve tres de sus dedos (el medio, el anular y el meñique), cada uno se mostrará igualmente como un dedo; en tanto considerados como dedos no importa dónde se les vea (en medio o en un extremo), cómo se les vea (blanco o negro, grueso o delgado), "porque en todo ello no se ve obligada el alma de los más a preguntar a la inteligencia qué cosa sea un dedo, ya que en ningún caso le ha indicado la vista que el dedo sea al mismo tiempo lo contrario de un dedo" (2006, 523d).

En cuanto a su grandeza y pequeñez, sin embargo, la vista no los distingue suficientemente, pues el mismo dedo se mostrará grande o pequeño en relación con los otros, de acuerdo a si se encuentra en medio o en el extremo. Asimismo, si presiono uno mis dedos, uno podría parecerme más blando que otro, pero más duro que otro; si comparo su grosor, el anular parece más grueso que el meñique, pero más delgado que el medio. Así actúa cada uno de los sentidos "viéndose ante todo obligado a encargarse también de lo 
blando el sentido que ha sido encargado de lo duro, y comunicando este al alma que percibe cómo la misma cosa es a la vez dura y blanda” (2006, 524a).

En esos casos, dice Sócrates, es forzoso que el alma se pregunte con perplejidad qué entiende esta sensación por dureza, ya que de lo mismo dice que también es blando; y qué entiende por ligero y pesado, "puesto que llama ligero a lo pesado y pesado a lo ligero” (2006, 524b). Efectivamente, responde Glaucón,

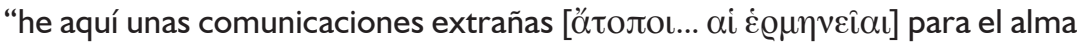
y que reclaman consideración” (2006, 524b).

¿En qué consiste la extrañeza de estas comunicaciones? Los sentidos reportan lo que perciben. En algunos casos, las cosas parecen suficientemente juzgadas por ellos. En otros, sus reportes parecen revelar algo absurdo: que lo mismo es, digamos, Fy su opuesto. En este caso, la vista percibe lo grande y lo pequeño no separado sino confundido. Del mismo modo el tacto con respecto a lo duro y lo blando. Los sentidos no los distinguen suficientemente, sino que revelan estas propiedades de manera deficiente. En casos semejantes, dice Sócrates, el alma comienza por llamar al cálculo ( $\lambda$ o $\gamma\llcorner\sigma \mu o ́ v)$ y la inteligencia e intenta investigar con ellos "si son una o dos las cosas anunciadas en cada caso" (2006, 524b). Si resultan ser dos, continúa, cada una de ellas aparecerá como una y distinta de la otra, de modo que, "si cada una de ellas es una y ambas juntas son dos, las concebirá a las dos como separadas, pues si no estuvieran separadas, no las concebiría como dos, sino como una" (2006, 524c).

Hay elementos que nos permiten comparar este pasaje con el del Parménides. Unos dedos parecen pertenecer a esa clase de objetos que son tales como los percibimos, mientas que las cosas grandes y pequeñas formarían parte de aquella otra clase a las que les corresponde una Idea (la grandeza y la pequeñez) que se distingue de sus instancias sensibles. Esta diferencia radica en que los objetos de la última clase pueden "recibir opuestos" o, dicho de otra manera, aparecen como grandes y pequeñas a la vez, así como los palos aparecían iguales y desiguales, mientras que ni la grandeza ni la pequeñez ni la igualdad pueden aparecer como sus opuestos. En vista de los pasajes vistos, ipodemos concluir que establecen un criterio que determina sobre qué cosas hay ideas y sobre qué no? Hay intérpretes que sugieren que sí. 


\section{§ 4. El argumento de los opuestos}

Como he mencionado, un curso de pensamiento usualmente adoptado al momento de interpretar el pasaje de los dedos es pensar que su propósito es demostrar la existencia de las Ideas. Allen (196I, 328-329) reconstruye el pasaje como expresando el siguiente argumento.

Al menos para pares de predicados como 'grande' y 'pequeño', 'ligero' y 'pesado', 'suave' y 'duro', cada vez que uno de ellos sea aplicable a algo, también lo será su opuesto. Ello es así porque estos predicados son relacionales: si $x$ es grande, lo es en relación con un y más pequeño que él, si es pequeño, lo es en relación con un $z$ más grande que él. Pero no hay algo así como el $x$ más grande, porque siempre habrá algo más grande que él con el cual puede ser comparado. Por lo tanto, en tanto que es grande, será pequeño a la vez. Precisamente por ello es que estos predicados implican su opuesto. No hay ninguna contradicción, entonces, en el hecho de que algo pueda ser predicable como grande y pequeño ${ }^{3}$, sino que es claramente consistente hacerlo.

Pero si estos predicados implican su opuesto, entonces su significado no puede ser identificado con aquellas cosas a las que se aplican. Supongamos que $F$ es un predicado y que $\mathrm{G}$ es su opuesto. Al ser opuestos, su significado será distinto. Pero si todo lo que es $F$ también es $G$ y viceversa, y si tomamos el significado de $F$ como lo que es $F$ (los F's) y el significado de $G$ como lo que es G (los G's), entonces el significado de F será el mismo que el de G. Absurdo.

Allen subraya el parecido de este argumento con el argumento que hayamos sobre piedras y palos iguales en el Fedón. Asimismo, asegura que hayamos el mismo argumento en el pasaje 475-e-476a de República $V$. En este pasaje se habla de lo bueno y lo malo, lo justo y lo injusto, lo bello y lo feo. Para que funcione, términos como 'bueno' y 'malo' tienen que ser analizados también relacionalmente, de manera que su significado es establecido en términos de mejor y peor en una escala comparativa. Dado que lo mismo puede ser mejor que otra cosa pero peor que otra, el mismo argumento se aplica. Finalmente, para Allen este argumento “(...) throws light on the question of what sorts 
of Forms there are. Substantive terms such as "finger" have no contraries (...), and are not relational. The argument form opposites does not establish Forms for such terms, and the discussion of 523a ff. strongly suggests that there are no such Forms (cf. esp. 524d9-525a2). This is presumably why Socrates in the Parmenides is in doubt whether substantival terms do not refer to "just the things we see," and why the only clear Forms in the middle dialogues are opposites. (...). It seems likely that, in the middle dialoges, there are no Forms of substances" (1961, 329, cursivas añadidas).

Sin embargo, algo importante se está perdiendo en esta interpretación. En 476a encontramos que "(...) lo mismo podría decirse de lo justo y lo injusto y de lo bueno y lo malo y de todas las Ideas, que cada cual es algo distinto, pero por su mezcla con las acciones, con los cuerpos y entre ellas mismas, se muestra cada una con multiplicidad de apariencias" (Platón 2006, 476).

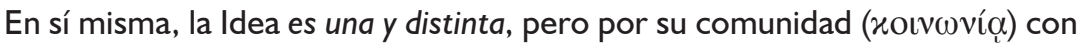
cuerpos, acciones y con las otras ideas, aparece múltiple. Es decir, en relación con otras cosas, la idea aparece múltiple; en sí misma, sin embargo, la Idea es una unidad distinta. Sócrates establece así el siguiente paralelo:

$\begin{array}{lll}\text { en sí } & : & \text { en relación con } \\ \text { Ser } & : & \text { aparecer } \\ \text { Unidad } & : & \text { multiplicidad }\end{array}$

Estos, a mi parecer, son los términos en los que debe leerse el pasaje del Fedón y de República $\mathrm{V}$ y VII y, en general, cualquier pasaje que establezca un contraste entre la Idea y las cosas que participan de ella. Por una parte, la Idea de Igualdad aparece múltiple por su relación con palos y piedras, relación en virtud de la cual estos son iguales. Por otra parte, en sí misma, la lgualdad es una y distinta no solo de las cosas sensibles que participan de ella, sino también de su opuesto, la Diferencia. El pasaje del Fedón así como el del libro V de la República no establecen una diferencia entre el "significado" de un término y las cosas a las cuales se aplica, entre su intensión y su extensión. El énfasis es ontológico, no semántico. Lo que establece son modos de ser: en sí y por relación. Bajo la diferencia de estos modos es que también debemos leer el pasaje de los dedos del libro VII. 


\section{§ 5. La perspectiva de los sentidos}

El énfasis del pasaje aludido no está en demostrarnos que las Ideas existen y qué tipos de Ideas hay. El énfasis está en el seguimiento de un proceso que culmina con el alma encontrándose en una situación cognitiva distinta a aquella en la que se hallaba cuando percibía lo mismo como grande y pequeño. Y esa es la razón por la cual "lo que los sentidos reportan", es decir, aquellas comunicaciones extrañas, son un elemento repetido y enfatizado en el pasaje. Como observa Allen (196I, 328), es perfectamente consistente decir de un dedo que es pequeño y grande a la vez en relación con otros dedos. La aporía en la que cae el alma de quien observa esto no es que el dedo sea grande $y$ pequeño a la vez, sino en que lo grande aparece como pequeño y lo pequeño como grande. Y ello es así porque los sentidos informan insuficientemente al alma lo que lo grande y lo pequeño son en sí mismos, a diferencia de lo que es un dedo. La deficiencia de los sentidos para distinguir la grandeza de la pequeñez es lo que hace que el alma abandone la perspectiva sensorial y pase a un estado cognitivo distinto, uno que le permita distinguir adecuadamente la pequeñez de la grandeza.

Julia Annas, sin embargo, considera que el lenguaje de Platón en este pasaje, que hace sonar a la inteligencia y a los sentidos como dos agentes independientes de juicio, "is seriously misleading" (198I, 22I). Lo que es confuso y equívoco para Annas es que el pasaje sugiere que los sentidos por sí mismos son competentes para juzgar lo que es observable, mientras que la inteligencia lo es sobre aquello que no es observable sino inteligible, lo cual no es el punto. Annas, como Allen, cree que lo esencial en el pasaje es la demostración de cierto tipo de ideas a través de comparar no experiencias cognitivas específicas, sino "conceptos": conceptos como 'dedo', que pueden ser aplicados adecuadamente a partir de nuestra experiencia sensible $y$, por otra parte, conceptos como 'grande', cuya aplicabilidad resulta problemática a la base de esa experiencia. Así, la distinción es entre conceptos que, como grande y pequeño, solo pueden ser propiamente entendidos a través del trabajo de la inteligencia, y conceptos como dedo, para cuyo entendimiento basta la percepción sensible de un dedo de la mano. De esta manera, en su opinion, “(...) we see an idea which be further developed, that in thinking we are doing something, actively reacting to a phenomenon, whereas in perceiving we are just passively taking it" (198I, 219). 
Ahora bien, en ningún lugar del pasaje la percepción sensible es descrita como un estado pasivo del alma, ni mucho menos. Al contrario, activamente los sentidos "informan" al alma (Burnyeat 2012, 77) y, como hemos visto, es precisamente la insuficiencia de esa información lo que hace al alma preguntarse sobre la grandeza y la pequeñez, distinguirlas y definirlas.

¿En qué consiste la actividad de los sentidos? Quizás podemos entenderla mejor reexaminando los juicios que produce en el caso del examen de los tres dedos. Si observamos el meñique, el anular y el medio de una de nuestras manos y nos preguntásemos “iqué son?”, y respondiésemos “dedos”, parece que estaríamos juzgándolos correctamente. Ahora, si observando el anular nos preguntásemos “iqué es?" y respondiésemos "grande”, nuestro juicio en este caso sería parcial y no absoluto. Porque nuestro anular es grande en relación con el meñique. Asimismo, si nuestra respuesta fuese "pequeño", también nuestro juicio sería parcial y no absoluto, pues la pequeñez de este dedo lo es en relación con el medio. ¿Qué elementos están tomando parte en estos juicios? Ciertamente, un contexto. De acuerdo al contexto en el que algo es visto, tocado, etc., lo mismo aparecerá como F y su opuesto. Por ejemplo, es en el contexto de los tres dedos (de la posición de uno en el medio de los dos y de los restantes en los extremos) que el dedo anular aparece grande en relación con el meñique, pero a la vez pequeño en relación con el medio; así mismo, aparece grueso en relación con meñique y delgado en relación con el medio, etc. Ello revela lo siguiente: (I) los objetos sensibles siempre son perceptibles en un contexto y (2) propiedades como grandeza o pequeñez, cuando son predicadas de estos objetos, siempre son relativas a él.

$\mathrm{Si}$, situados en este contexto, nos preguntásemos “iqué es un dedo?" y respondiésemos señalando los tres dedos que observamos, (aparentemente) no habría problema con ello. "Ser un dedo" aparece como un predicado que el meñique, el anular y el medio satisfacen completamente. Por otra parte, si nos preguntásemos “iqué es grande?” y respondiésemos señalando el anular $y$, al preguntarnos “iqué es pequeño?” respondiésemos con el anular también, nos daríamos cuenta de algo, a saber, que lo grande y lo pequeño aparecen como lo mismo. Lo que sucede es que el ser grande y el ser pequeño del dedo anular es relativo y no absoluto $y$, por lo tanto, situados cognitivamente en este contexto, lo grande y lo pequeño aparecen como las cosas grandes y II6 pequeñas que, (iaporía!) resultan ser las mimas. Para superar este problema, 
el alma debe situarse de otra manera, por así decirlo. Lo debe hacer de manera tal que pueda distinguir lo grande y lo pequeño y se darse cuenta que (I) ambos son dos $y$, por lo tanto, cada uno es uno, pero que para saber por qué son dos y no uno, es decir, para saber por qué cada uno es uno, (2) debe preguntarse qué es cada uno, qué es la grandeza y qué es la pequeñez en sí y no en relación con nada más.

Observarse los dedos contrae beneficios filosóficos. Al final del proceso, la situación cognitiva del alma no es la misma. Ha experimentado un ascenso. La situación en la que se encuentra ahora es una tal que le permite considerar su experiencia ordinaria de mirarse los dedos como dependiente de un contexto y de una perspectiva. Ha pasado de considerar la grandeza con relación a un dedo en relación con otro a considerar lo que es la grandeza en sí. Si recordamos el paralelo que establecimos anteriormente, ha pasado del ámbito de las apariencias (grandeza de un dedo, parcial y relativa) al ámbito del ser (grandeza en sí). En última instancia, esta experiencia sirve de modelo a Platón para describir un estado en el cual el alma se da cuenta de que toda su experiencia ordinaria, basada en los sentidos, depende de una perspectiva y de un contexto, un contexto que es establecido (al menos en parte) por el aparato cognitivo que usamos para la vida diaria: la opinión. Opinión es lo que tenemos cuando el alma se dirige hacia seres que admiten perspectiva $y$ cuyo ser es relativo (Burnyeat 2000, 2I).

Ello es aplicable no solo en relación a pares de opuestos relativos, como grandeza y pequeñez, sino también a pares de opuestos contrarios ${ }^{4}$, como vemos en República $\vee(476 a-477 b)$, con respecto a las cosas, acciones bellas, justas y buenas, en relación con lo justo y lo injusto, la belleza y la fealdad, la bondad y la maldad. Cualquier acción que consideremos justa, cualquier cosa que consideremos bella, tiene la capacidad de recibir opuestos. Devolver lo prestado a los amigos, por ejemplo, puede ser un tipo de acción en ciertos contextos justa e injusta en otros, como lo explicita Sócrates en República I.

$4 \quad$ Según Aristóteles, dos cosas se dicen opuestas entre sí en al menos cuatro sentidos: (i) como relativos (el doble y el medio), (ii) como contrarios (bueno y malo), (iii) como privación y posesión (ceguera y vista), o (iv) como afirmación y negación (está sentado, no está sentado) (Aristóteles 2002, Ilbl7). 
Ahora, irealmente, después de todo, encontramos un argumento que busque demostrar la existencia de las Ideas y que, con ello, también nos demuestre qué tipos de ideas existen? No solo no hayamos uno en la interpretación ofrecida, sino que hay al menos dos razones más para descartar esa posibilidad. La primera es el contexto del pasaje de los tres dedos. Está situado en la discusión acerca de cómo hacer que los futuros gobernantes "salgan a la luz" a través de una enseñanza "que atraiga el alma desde lo que nace hacia lo que es" (Platón 2006, 52 Id). El contexto es la discusión de la educación del filósofo. Sócrates ilustra el "ascenso" que debe proporcionar esta educación con una experiencia ordinaria: examinarse los dedos. Y si este ascenso es de lo que "nace" a lo que "es", ciertamente la existencia de lo que "es" debe estar presupuesta. Naturalmente, "lo que es" refiere a las formas platónicas. Esta presuposición se hace evidente cuando tomamos en cuenta al interlocutor de Sócrates en esta parte del diálogo, y esta constituye la segunda razón. Glaucón, así como su hermano Adimanto, y a diferencia de los interlocutores anteriores, no es alguien que desconozca la hipótesis de las Ideas, sino que está familiarizado con ella. Es precisamente por ello que un argumento de parte de Sócrates dirigido a Glaucón con la intención de demostrar la existencia de las Ideas no tendría sentido, es algo que ya es presupuesto por ambos.

\section{$\S 6$. ¿Objetos sin ideas?}

Ahora bien, si mantenemos la hipótesis de que solo hay ideas para pares de predicados de propiedades opuestas, ello nos deja con una amplia gama de predicados (predicados substanciales, como los llama Allen) sin una Idea correspondiente $y$, por lo tanto, una amplia gama de objetos a los cuales esos predicados se aplican sin la participación en una Idea. Dedos, seres humanos, palos y pelos no necesitarían de la participación en una Idea para ser lo que son.

La existencia de un dominio de objetos a los que no les corresponde una Idea $^{5}$ ha sido reconocida en otras interpretaciones y ciertamente es una consecuencia

$5 \quad$ Estrictamente, ningún objeto no participa de algún modo en una Idea, ya que Ideas como Ser, Identidad, Diferencia, Reposo, Movimiento, son determinaciones fundamentales de cualquier entidad. Lo que quiero decir, en cambio, es que dedos, para ser precisamente dedos, no necesitan de la participación en una Idea de Dedo, y así con los otros ejemplos discutidos. 
de la interpretación que hemos venido objetando. Por ejemplo, el profesor David Sedley ha planteado reinterpretar el pasaje del "símil de la caverna" $(2013,115-116)^{6}$. Tomando el interior de la caverna como representando la totalidad del ámbito sensible, se concentra en el análisis de aquellos ítems cargados por encima del murillo. Él propone corregir la tradicional traducción del pasaje (5I4b-5I5a) como diciendo que aquellos hombres cargan:

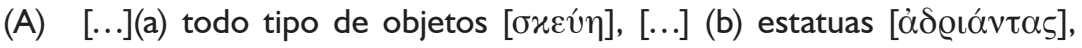
y (c) otras imágenes [ $\zeta \hat{\omega} \alpha]$, hechas de piedra, madera y todo tipo de materiales.

En vez de seguir la traducción tradicional que dice:

(B) [...] (a) toda clase de objetos [...] y (b) estatuas de hombres o (c) [estatuas de] animales hechas de piedra, madera y de toda clase de materiales ${ }^{7}$.

La relación entre (b) y (c) ha sido mal interpretada en traducciones como

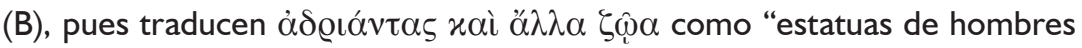

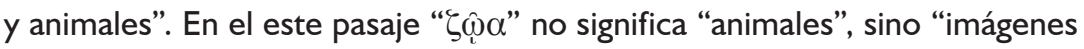
artísticas”, sin referencia animales en particular. Ello puede verse reflejado

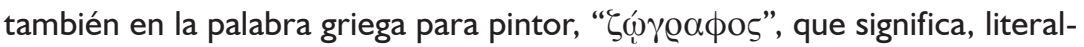
mente, "pintor de $\zeta \hat{\omega} \alpha$ ", donde la ocurrencia de " $\zeta \hat{\omega} \alpha$ 'no tiene el significado específico de "animales" (lo que haría que la expresión griega signifique "pintor de animales"), sino que su significado es el de "imágenes en general" .

Aclarados así los sentidos de las palabras, la lista exacta de las cosas llevadas por encima del muro dentro de la caverna debe contener:

(a) 'objetos' de todo tipo;

(b) imágenes de seres humanos;

(c) imágenes de otras cosas que no sean seres humanos.

6 Debo remarcar de que este ensayo no descansa en aceptar la interpretación propuesta por Sedley del pasaje República 514b-515a. Yo mismo no la aceptaría si es que no se estudia con cuidado las consecuencias que esta interpretación puede tener en la correspondencia de estos objetos del "símil de la caverna" con los objetos del segmento de la pistis del "símil de la línea" (los animales que nos rodean, todas las plantas y el género entero de las cosas fabricadas).

7 Traducción de Pabón y Fernández Galiano (Platón 2006, 5I5a).

8 Las razones filológicas y filosóficas específicas para esta interpretación son desarrolladas por Sedley $(2013,115-116)$. 
Al respecto, Sedley remarca lo siguiente: dado que (b) y (c) representan juntas todas las imágenes posibles, los meros 'objetos' del grupo (a) no son imágenes o representaciones. En tanto (b) y (c) son imágenes, podemos decir son seguridad que sus originales se encuentran fuera de la caverna, que representa el ámbito inteligible. Ahora bien, los objetos (a), al no ser estrictamente imágenes de nada, no tienen originales fuera de la caverna. Si los objetos de (c) y (b) se relacionan con los objetos fuera de la caverna como los objetos sensibles con las ideas de las cuales participan, es decir, como imagen y original, si ello es así, entonces los objetos (a) no tendrían una idea como original de la cual participarían, al no ser imágenes. La propuesta interpretativa de Sedley es que, con el grupo (a), Platón estaría delimitando una clase de objetos a los que no corresponde una Idea. ¿Qué tipo de objetos podrían ser, en todo caso, aquellos que caen bajo la clase (a) y a los que supuestamente no corresponde ninguna Idea? Sedley considera una serie de alternativas, pero la que a mí me interesa discutir ahora es la última: la clase de objetos (a) representa objetos tales como dedos que, de acuerdo con el pasaje de República VII, pueden ser adecuadamente discriminados por los sentidos, de modo que no se necesita de actividad de la inteligencia para discriminar qué son`. En la siguiente sección quisiera, finalmente, abordar si "aquello que es un dedo" o "aquello que es un pelo" puede ser realmente discriminado adecuadamente por los sentidos a partir de lo que encontramos en los pasajes concernientes.

\section{§ 7. La opinión de la mayoría}

Si prestamos atención al cuidado y al sutil reparo con el que Sócrates introduce la distinción entre objetos de la sensación que llaman o no a la inteligencia a juzgarlos, encontramos que, con respecto a observarse los dedos, dice que:

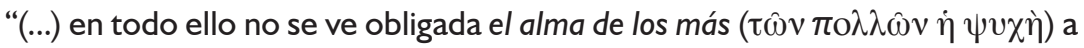
preguntar a la inteligencia qué cosa sea un dedo, ya que en ningún caso le ha indicado la vista que el dedo sea al mismo tiempo lo contrario de un dedo" (Platón 2006, 523d, cursivas añadidas).

9 Sedley no se decanta explícitamente por esta alternativa, solo presenta pros y contras (2013, II8-120). El propósito en su texto es decir que la existencia de un grupo de objetos sin una Idea correspondiente es una de las razones para sostener que Platón no postuló la hipótesis de las Ideas como una teoría sobre universales, en el contexto de una discusión acerca de si las formas platónicas son ese tipo de entidades.. 
El énfasis es puesto en lo que estimula intelectualmente al alma de la mayoría: Sócrates está ilustrando la experiencia de ascenso del alma a través de una experiencia ordinaria que llamaría su atención. Pero de ello no se sigue que un dedo (o la propiedad de ser un dedo) no merezca una investigación que postule o identifique una Idea de Dedo (Harte 2008, 200). Tampoco se sigue de ello que las propiedades que estimulan el alma de la mayoría y las que no sean un criterio que demarca el límite entre objetos a los que corresponde una Idea y aquellos a los que no, que delimite las clases (b) y (c), por un lado, y la clase (a), por el otro.

La alusión a los más es importante. Volvamos al pasaje del Parménides con el que abrimos nuestra investigación. Sócrates se muestra incómodo con la posibilidad de Ideas de cosas como pelo, basura, barro. No tan incómodo, pero igualmente dubitativo con respecto a Ideas de hombre, agua y fuego. En todo caso, ha abandonado tales hipótesis por miedo a caer en sin sentidos. Quizás con una sonrisa indulgente, Parménides le dice: “(...). Claro que aún eres joven, Sócrates, y todavía no te ha atrapado la filosofía, tal como lo hará más adelante, según creo yo, cuando ya no desprecies ninguna de estas cosas. Ahora, en razón de tu juventud, aún presentas demasiada atención a las opiniones de los hombres" (Platón 2015c, 130e, cursivas añadidas).

Parménides sugiere que la opinión de la mayoría es lo que hace que el joven Sócrates repare en esencias para cosas como agua y nimiedades como pelos, pues para la mayoría, podría decirse, esas cosas no son otra cosa que lo como las vemos. Por otra parte, no es casual, a mi parecer, que sea el viejo Sócrates de la República quien precise qué cosas aparecen como confusas, conflictivas y exigiendo una explicación para la mayoría. Este es un Sócrates que puede ilustrar con casos que llamen la atención de las intuiciones de las almas ordinarias pues es él quien puede distinguir entre lo que llama la atención de la mayoría y lo que podría estimular intelectualmente a unos pocos. Los casos que no llaman la atención de la mayoría son, precisamente, casos en los cuales las cosas no se muestran como siendo de otra manera para los sentidos, de manera que esta (la mayoría) infiere que ellas son tal como ellos nos las presentan, tal como las vemos.

Aun así, queda la pregunta, en todo caso, de cómo podría resultar intelectualmente estimulante la percepción de un dedo en tanto dedo, de una piedra, 
del agua, de un pelo. Annas incluso repara en decir que si todo concepto fuera como el de dedo, de modo tal que pueda ser aplicado a todo lo que experimentamos de manera absoluta y sin la posibilidad de aplicar el opuesto, entonces nunca sentiríamos la insatisfacción intelectual que nos conduciría a conocer las Ideas de grandeza y pequeñez. Asimismo, si todo concepto fuera como "grande", de modo que su aplicación a lo que experimentamos siempre lleva a la aplicación de su opuesto también, no sentiríamos ninguna insatisfacción intelectual, "because there would be nothing to compare our unsatisfactory performance with, no reason to think that unqualified application of any concept was ever posible" (I98I, 22I-222).

Pero como hemos visto, cabe la posibilidad de que alguien inusualmente inteligente encuentre la experiencia de describir a los dedos como tales problemática. Como vimos, estos son objetos sensibles (percibidos y juzgados por los sentidos) que admiten la presencia simultánea de opuestos. Sincrónicamente, el alma percibe que el mismo dedo es grande y pequeño, duro y blando, grueso y delgado (con respecto a los otros dedos). Así es como el alma de la mayoría tiene estas percepciones confusas. Sin embargo, un alma con más capacidad de abstracción, abstrayéndose del momento presente, diacrónicamente, se preguntaría: ¿un dedo siempre se muestra como un dedo, un hombre como un hombre, una piedra como una piedra?

Encontramos ayuda en un pasaje del Timeo (50a-b). Allí se dice que si alguien que moldea un trozo de oro, cambiando sin cesar su figura de una en otra, fuese interrogado por alguien que, mirando lo que moldea, le preguntase "qué es", lo más correcto sería decir que es oro, pero no afirmar que es un triángulo o cualquiera de las otras figuras, puesto que cambiaría mientras se afirmase tal cosa (White 1992). La pista es que, diacrónicamente, vistas considerando la variable del tiempo, las cosas son y dejan de ser lo que son, admitiendo así opuestos de otro tipo ${ }^{10}$. Tomemos el caso de un hombre. De él se puede decir que es (=existe) y que, una vez muerto, que no es. Cualquier hombre particular está no solo sujeto al cambio, sino también a la muerte ( $y$, en ese sentido, a dejar de ser hombre, en un sentido específico). Si es que lo que es ser un hombre (un ser humano) no puede dejar de serlo, ni Sócrates, 
ni yo, ni ningún hombre particular puede serlo, debe ser algo distinto". Algo cuya definición sería satisfecha solo parcialmente por individuos particulares, pero solo absolutamente por la Idea de Hombre. Si es así, lo mismo sería el caso de los dedos, pelos y piedras. Así, "lo que se da en un caso, también se da en los otros casos".

\section{Bibliografía}

Platón, 1963. The Republic of Plato, vol. I y II. Cambridge: Cambridge University Press. —2006. República. Traducción de J.M. Pabón y M. Fernández-Galiano. Madrid: Centro de Estudios Políticos y Constitucionales.

—2015a. Fedón. Traducción de C. García Gual. En: Diálogos III. Madrid: Editorial Gredos.

— 2015b. Parménides. Traducción de G.R. Echandía. Madrid: Alianza Editorial.

—2015c. Parménides. Traducción de Ma. Santa Cruz. En: Diálogos V. Madrid: Editorial Gredos.

— 2015d. Timeo. Traducción de Ma. Ángeles Durán y F. Lisi. En: Diálogos VI. Madrid: Editorial Gredos.

Allen, R.E., 1961. The Argument from Opposites in Republic V. The Review of Metaphysics 15 (2), 325-335.

Annas, J., 1981. An Introduction to Plato's Republic. Oxford: Clarendon Press.

Aristóteles, 2002. Categories and De Interpretatione, Traducción de J.L. Ackrill. Oxford: Clarendon Press.

Burnyeat, M., 2012. Plato on the grammar of perceiving. En: Explorations in Ancient and Modern Philosophy, M. Burnyeat. Cambridge: Cambridge University Press, 70-98. - 2000. Plato on Why Mathematics is Good for the Soul. En: Mathematics and Necessity, ed. T. Smiley. Oxford: Oxford University Press, I-8I. https://doi.org/I0.1017/ СВО97805II974069.006

Harte, V., 2008. Plato's Metaphysics. En: The Oxford Handbook of Plato, ed. G. Fine. Oxford: Oxford University Press, 192-2/4. https://doi.org//0.1093/ oxfordhb/9780195182903.003.0008

Scoon, R., 1942. Plato's Parmenides. Mind 5I (202), II5-133. https://doi.org//0.1093/ $\operatorname{mind} /$ LI.202.II5

II Sedley propone definir "ser hombre" como una función específica, definible como la de acoger un alma racional en una estructura que le permite desarrollarse moral e intelectualmente en una vida prolongada pero finita $(2016,18)$. 
Sedley, D. 2016. An Introduction to Plato's Theory of Forms. Royal Institute of Philosophy Supplement 78, 3-22. https://doi.org/10.1017/SI358246II6000333

- 2013. Plato and the One-over-Many Principle. En: Universals in Ancient Philosophy, eds. R. Chiaradonna y G. Galluzzo. Pisa: Edizioni della Normale, II3-I37.

White, N. P. 1992. Plato's metaphysical epistemology. En: The Cambridge Companion to Plato, ed. R. Kraut. Cambridge: Cambridge University Press, 277-3I0. https://doi. org/10.1017/CCOL0521430186.009 